\title{
Impact of TV Advertisement on Children Attitude in Karachi
}

\author{
Shaista Kamal Khan*, Sheheryar Syed**
}

\begin{abstract}
Primarily advertisement influences children and their behavior in the society. Their impacts on the children are universal. The severity of television influence varies from child to child. Initially, children face problems in deciphering television programs. In Pakistan, most advertising agencies now target children through advertisements especially when advertising consumer products like children's toys, chocolates, confectionary bars, tooth paste etc. In Pakistan, advertising agencies understand the role of children in buying process of parents. Most advertising agencies now target children through advertisement. The purpose of this research to analyze the response of children's attitude towards television advertising. This research will also help in identifying children's perception about the advertisement and at what contexts children may like/dislike any commercial advertisement To analyze this research, the researcher use the quantitative approach correlation. The finding of this research is that children's are now more aware about the good and bad aspects of TV advertisement so the marketer should understand the psychic of children's before launching any advertisement. The study focuses exclusively on high school children in Karachi.
\end{abstract}

Key Words: Advertising, Children, Attitude.

\section{Introduction}

The objective of this research is to identify the children attitude towards TV advertisement. Television is one of the strongest media in a society and due to its reach and popularity has the power to influence culture of a particular country. However, it may be noted that among a surplus of benefits of television offers, there are some negative aspects as well. Primarily it influences children and their behavior in the society. Their impacts on the children are general. The ruthlessness of television influence varies from different children. It consists on aspects as age and traits of the child, and under the direction of their parents.

Television viewing has its pros and cons. On the negative side, excessive viewing leads to laziness and inactivity and thus contributes towards childhood obesity. Children who watch television a lot are found to be the ones who are not involved in healthy and sport activities and are consumers of high fat foods commonly known as junk food. Commercials can also be regarded as influencing one's behavior unfavorably. They do not reveal the foods children should eat to keep fit. Television audience tends to get a good judgment of relaxation when they are watching television. Sports activities and hobbies are the source of energy whereas television viewing is a source of depletes energy.

Television is a pervasive medium which is readily available to nearly all children. Most of the children the world over spend about three to four hours daily watching television. Initially, children face problems in deciphering television programs. But being quick learners, they can make rational decisions under proper guidance of the parents. Thus it is advisable for the parents of young children to monitor the television viewing habits of their children.

In Pakistan, most advertising agencies now target children through advertisements especially when advertising consumer products like kid's toys, chocolates, sweets bars, tooth paste etc. Research shows that Pakistani kids are very much aware about the features of television advertisements like truthfulness, communication of the idea, taste and influencing characteristics of the ads. Their behavior is also different about advertised and non-advertised brands. In Pakistan, advertising agencies understand the role of children in buying process of parents. Most advertising agencies now target children through advertisement. Many advertising agencies use child role models in advertisements related to consumer products like children's toys, chocolates, candy bars, milk (Nestle, Haleeb), tooth paste (Colgate, Aqua Fresh)

This research has been conducted to analyze the response of children's attitude towards television advertising. This research will also help in identifying children's perception about the TV advertisement.

\section{Advertising}

Advertising is a paid, uni-directional communication through a medium in which the support is identified and the message is controlled. It is used for publicity, public image, product placement, sponsorship, underwriting, and sales promotion (Kunkel and Gantz, 1992). Every major medium delivers these messages, include: tv, radio, magazines, newspapers, the Internet, and billboards". Advertising can be attributed as persuasive commercial messages for selling and informing consumers about new products (Kunkel and Gantz, 1992). 
Children's purchasing behavior and demand for goods seem to be influenced by TV commercials. Extensive research has been undertaken on the advertising effects on children's eating habits. Children food preference is highly dependent on television advertising (Borzekowski \& Robinson, 2001)

\section{Behavioral Effects of Advertising}

Since young children usually do not have the means to purchase products, behavioral effects are usually measured by children's preferences for products (Galst \& White, 1976; Robertson \& Rossiter, 1976), or by the requirements they make in reply to advertised products (Atkin, 1975; Sheikh \& Moleski, 1977). In behavioral research, children usually watch one or many ads, after which they are given a option from a series of products, which include the advertised brand (Gorn \& Florsheim, 1985; Gorn \& Goldberg, 1977, 1980). Researchers then often demonstrate that the advertising of a specific brand makes the child's subsequent choice of that brand more likely. A disadvantage of these studies is that the results that are found within a controlled laboratory setting may not be generalized to more naturalistic contexts (Young, 1990). A number of behavioraleffects studies have attempted to solve this problem by investigating advertising effects. The study has focused on the impact of advertising on children's purchase requests by surveying parents (Caron \& Ward, 1975; Robertson et al., 1989)

\section{Exposure to Advertising}

Children's exposure to advertising is dependent on their viewing habits. Those Children who watch TV frequently are more vulnerable to parameters such as increased Obesity and chronic sickness risk, greediness etc. (Bushman and Cantor, 2003).

The consequences of TV advertising directed at children have been a matter of debate throughout this decade (see, e.g., ACT 1970). One particular concern relates to children of lower income families. One expert, Dr. Frederic Greene, writes, It is an especially tragic misuse of the airways, the gap between the aspirations raised by such advertising and its fulfillment (Greene 1973, p. 65).

Research shows that children constitute a major customer market, with direct purchase power for food and drink and sweets and indirect influence while shopping for big-ticket items (Halan, 2002; Singh, 1998).Today parents have become more accept of kids choices (John, 1999).

Rossiter's study identifies some of the variables regarding children attitude that are given below:

1. Truth: Television commercials tell the truth.

2. Annoy: Most TV commercials are in poor taste and very annoying

3. Good only: TV commercials tell only the good things about a product.

4. Like: I like most television commercials

5. Persuade: TV commercials try to make people buy things they don't really need.

6. Believe: You can always believe what the people in commercials say or do.

7. Best: The products advertised the most on TV are always the best products to buy.

As children are very much aware of TV advertisements and they know good and bad effects of them. Marketer should consider the children's psychic before launching any advertisement. Children also know the extent of honesty in add. So for the advertisers it's very essential to realize that children are not ignorant from the content of their campaigns.

\section{Children's Reactions to buying behavior versus Advertising}

Although this question has not been studied with children, some research has been conducted among adult populations that show that consumers do respond to advertising and buying behavior in distinctive ways. One useful concept in this regard is the "integrated information response" model (Smith and Swinyard 1982). This model suggests that, because consumers know that advertisers wish to present their brands in a favorable light, they react to ads by partially discounting claims and forming tentatively held ("lower- order") brand beliefs and attitudes. In line with Rossiter's study, children's attitudes towards television advertising were measured on a 7-item scale. The selected scale focuses on the range of cognitive and affective reactions towards television advertising in terms of perceived truthfulness, potential annoying qualities, believability of characters, and trust worthiness as guidance to product purchases (Pereira 1996).

\section{Conceptual Framework}

On the basis of previous researches, researcher made this framework by studying on a variables described below by conducting a study on Children Attitude towards TV Advertisements.

In this research the following variables to find out the children's attitude towards TV advertisement. 
Truth

Television commercials tell the truth. Younger children's understanding of the nature of television ads appears to improve as they mature and their belief in the truthfulness of advertising tends to decline. ( Unnikrishnan \& Bajpai 1996).

Annoy

Children feel the annoying qualities of advertisements and have agreed that most TV commercials are of poor taste and are very annoying. (Unnikrishnan \&Bajpai 1996)

\section{Good only}

Adults appearing on television are sanctioning and encouraging the use of a product, then to a young child's mind, it follows that the product must be good (Martin 1997).

Like

Children with positive attitudes towards advertising, tend to like advertisements and behave in a manner that is consistent with their professed attitudes. (Sherry et al. 1999).

\section{Persuade}

Younger children are also poor at making comparative judgments regarding alternative. Products advertised and are less aware of an advertisement's persuasive intent. For them, advertisements introduce new products and new things that they should have. (McNeal \& Ji 1999).

\section{Believe}

Children also consider the realities and beliefs about the products and will show preferences. Children may in turn communicate these opinions in terms of purchasing behavior or ask their parents to purchase the product (McNeal \& Ji 1999).

\section{Best}

The very best creative talents are employed to design a television ad; it will be ineffective unless the child pays attention to it. Children tend to pay more attention towards the commercials but understand very little about them. (Martin 1997).

\section{Research Question}

Q: what is the impact of TV advertisement on children's attitude?

\section{Research Approach}

The study is descriptive in nature and research follows the quantitative approach toward measure the importance of factors according to the perception of children's, factors are already define above. Quantitative research refers to the logical empirical study of quantitative properties and happening and their dealings.

\section{Sampling Procedure}

There are 15 high schools in North Nazimabad which are private and providing education till matriculation. This survey involved 2 karachi high school from area of North Nazimabad. A total of 75 school children aged 10-15 years will be selected on the basis of (Kobasigawa, 1977) study. The Convenience sampling method is used according to the convenience of getting data from the school of Karachi.

\section{Research instrument}

Seven items is used to measure children's television advertising responses. Seven questions is formed and adapted from (Rossiter, 1977) scale. Currently tried to find out that Karachi school children have significant know how of TV advertisements or not.

To identify the children's attitude towards the TV advertisement the researcher used Likert-scale where 1 denoted as strongly disagree and 4 strongly agree.

Table 3.1: List of research variable

\begin{tabular}{|c|l|l|}
\hline S.No. & Variable Name & \multicolumn{1}{c|}{ Variable Description } \\
\hline 1 & Truth & TV commercials tell the truth. \\
\hline 2 & Annoy & Most TV commercials are in poor taste and very annoying \\
\hline 3 & Good only & TV commercials tell only the good things about a product. \\
\hline 4 & Like & I like most television commercials \\
\hline 5 & Persuade & TV commercials try to make people buy things they don't really need. \\
\hline 6 & Believe & You can always believe what the people in commercials say or do. \\
\hline
\end{tabular}




\begin{tabular}{|c|l|l|}
\hline 7 & Best & The products advertised the most on TV are always the best products to buy. \\
\hline 8 & Want & After watching TV commercial I want to buy the product advertised \\
\hline 9 & Annoying & Most TV commercials are very annoying. \\
\hline 10 & Approved & I mostly like to buy products that are approved by celebrities. \\
\hline 11 & Usage & I like advertisements of the products that are use myself. \\
\hline 12 & Attract & Most TV advertisements do not attract me to buy those products. \\
\hline 13 & Reality & Mostly TV advertisements are not based on reality. \\
\hline 14 & Different & There is a big difference between the product features advertised on TV and actual usage. \\
\hline 15 & Not many & There are not many advertisements of children's products. \\
\hline
\end{tabular}

Above table 3.1 is defining the variables are using in our research, in which variable from 1 to 7 are predefined in theoretical framework and variables from 10 to 15 were added through a focus group.

\section{Data Analysis}

The data analysis has been performed through statistical software SPSS and relationship between TV advertisement and children attitude was explored. Descriptive statistics have been calculated and data relationships have been analyzed. For exploring the impact of TV advertisement on children attitude. In this research the researcher will analyze data through Correlation.

\section{Reliability Analysis}

After evaluating chronbach's analysis on all 15 variables, there is a result showing 0.367 chronbach' value. That value is defining very low consistency in result, so for achieving better reliability result, we delete different variables as basis on reliability rules. After removing 9 variables (table 4.1), reliability value becomes 0.682 , which is acceptable for further analysis. Below table shows stage wise deletion of variables.

Table: 4.1 variable exclusion Statistics

\begin{tabular}{|l|l|c|c|c|}
\hline Stages & Variables excluded & Reliability before exclusion & $\begin{array}{c}\text { Reliability after } \\
\text { exclusion }\end{array}$ & Inter item correlation \\
\hline 1 & Persuasive & 0.367 & 0.412 & -.087 \\
2 & Best & 0.412 & 0.435 & -.028 \\
3 & Usage & 0.435 & 0.453 & .005 \\
4 & Want & 0.453 & 0.485 & -.04 \\
5 & Believe & 0.485 & 0.528 & -.067 \\
6 & Mostly & 0.528 & 0.571 & -.058 \\
7 & Like & 0.571 & 0.597 & .074 \\
8 & Truth & 0.597 & 0.628 & .075 \\
9 & Not many & 0.628 & 0.682 & .020 \\
\hline
\end{tabular}

Above table showing the exclusion of variables which were not making correlation with other variables.

At stage 1, Persuasive was excluded from total variables. The reliability value before exclusion was 0.367 , after the excluding the variable the value of reliability increased to 0.412 .

At stage 2, Best was excluded from other variables. The reliability value before exclusion was 0.412 , after the excluding the variable the value of reliability improved to 0.435 .

At stage 3, Usage was excluded from total variables. The reliability value before exclusion was 0.435 , after the excluding the variable the value of reliability increased to 0.453 .

At stage 4, Want was excluded from total variables. The reliability value before exclusion was 0.453 , after the excluding the variable the value of reliability increased to 0.485

At stage 5, Believe was excluded from total variables. The reliability value before exclusion was 0.485 , after the excluding the variable the value of reliability improved to 0.528 .

At stage 6, Mostly was excluded from total variables. The reliability value before exclusion was 0.528 , after the excluding the variable the value of reliability increased to 0.571 .

At stage 7, Like was excluded from total variables. The reliability value before exclusion was 0.571 , after the excluding the variable the value of reliability increased to 0.597 .

At stage 8, Truth was excluded from total variables. The reliability value before exclusion was 0.597 , after the excluding the variable the value of reliability improved to 0.628 .

At stage 9, Not Many was excluded from total variables. The reliability value before exclusion was 0.628 , after the excluding the variable the value of reliability increased to 0.682 . 
Table 4.2: Reliability Analysis based on 6 items.

\begin{tabular}{|r|r|r|}
\hline & $\begin{array}{c}\text { Cronbach's Alpha } \\
\text { Based on } \\
\text { Cronbach's Alpha } \\
\text { Standardized Items }\end{array}$ & N of Items \\
\hline .682 & .685 & 6 \\
\hline
\end{tabular}

Above table shows the 0.682 chronbach's alpha value, which showing good consistency in data. Below table represents further variables which are now used in our research and their chronbach's alpha value represents that further deletion effects to the reliability of instrument.

Table 4.3: Reliability Instrument

\begin{tabular}{|l|r|r|}
\hline & $\begin{array}{c}\text { Scale Mean if Item } \\
\text { Deleted }\end{array}$ & $\begin{array}{c}\text { Cronbach's Alpha } \\
\text { if Item Deleted }\end{array}$ \\
\hline poor taste & 13.76 & .616 \\
good only & 13.56 & .631 \\
Annoy & 13.83 & .617 \\
attract me & 13.77 & .639 \\
Reality & 13.59 & .668 \\
different & 13.96 & .672 \\
\hline
\end{tabular}

\section{Factor Analysis}

Factor analysis is to find out a possible primary outline of relationships so that the data may be reordered and reduced into a small set of factors. From this it is possible to select the dependent variables. (R. J. Johnston, 1978.)

Table 4.4: Factor Analysis

\begin{tabular}{|l|c|c|}
\hline \multirow{2}{*}{} & \multicolumn{2}{|c|}{ Component } \\
\cline { 2 - 3 } & Depict & Ethnicity \\
\hline poor taste & .940 & \\
Annoy & .932 & \\
Reality & & .758 \\
Good only & & .655 \\
Different & & .647 \\
Attract me & & .604 \\
\hline
\end{tabular}

The result of factor analysis showing that there is two different factors which based on Depict (poor taste, annoy) and ethnicity (reality, good only, different, attract me). This result defines that these variables are highly correlated in term of TV advertisement on children's attitude.

\section{Mean Analysis}

Table 4.5: Mean Analysis

\begin{tabular}{|ll|r|r|r|r|r|r|}
\hline & & \multicolumn{1}{|c|}{ poor taste } & \multicolumn{1}{c|}{ good only } & \multicolumn{1}{c|}{ Annoy } & attract me & \multicolumn{1}{c|}{ reality } & different \\
\hline $\mathrm{N}$ & Valid & 75 & 75 & 75 & 75 & 75 & 75 \\
& Missing & 0 & 0 & 0 & 0 & 0 & 0 \\
Mean & & 2.7333 & 2.9333 & 2.6667 & 2.7200 & 2.9067 & 2.5333 \\
Minimum & & 1.00 & 1.00 & 1.00 & 1.00 & 1.00 & 1.00 \\
Maximum & & 4.00 & 4.00 & 4.00 & 4.00 & 4.00 & 4.00 \\
\hline
\end{tabular}

According to the results the variable Good Only has been rated at a quite high rate by the respondent children, as has the highest mean value of 2.93 which shows that the Pakistani kids have the complete understanding of commercials being shown on television and they have the believe that the commercials only tells the good things about the product, and not the bad things, as the prime objective of commercials are to ensure selling of the product. The Reality has the second highest mean value of 2.90 , which shows that the children also have the understanding that the commercials are not based on reality and they only represent the good features of the products, and not the bad ones, so the product can be sold out in the market. The variable Different has been rated as a lowest one 2.53 which also prove that the children are neither agree or nor disagree that there is the big difference between the product features advertised on TV and its actual usage. 


\section{Bivariate correlation}

Table: 4.6 Reliability Analysis - Scale (Inter-item Correlation Matrix)

\begin{tabular}{|c|c|c|c|c|c|c|}
\hline & poor taste & good only & annoy & attract me & reality & different \\
\hline poor taste & 1.000 & & & & & \\
\hline good only & .237 & 1.000 & & & & \\
\hline Annoy & .809 & .269 & 1.000 & & & \\
\hline attract me & .292 & .259 & .240 & 1.000 & & \\
\hline Reality & .069 & .280 & .115 & .371 & 1.000 & \\
\hline different & .157 & .343 & .124 & .174 & .245 & 1.000 \\
\hline
\end{tabular}

Reliability analysis in bi-variate correlation was used that is inter-item correlation among the items listed in the Table-4.6. According to Guilford (1973) procedure, for a well constructed test, item intercorrelations should be lie 0.10 and 0.60 (Rossiter, 1977). The present findings shows amongst all the all pairs (annoy-poor taste) are very strongly correlated as have correlation value of 0.809 . Whereas, all the others pairs have the positive correlation between them, as the value is lying between 0.1 to 0.6 (Good only-poor taste) (Attract me-poor taste) (Different-poor taste). On the other hand (reality-poor) taste is the only pair that has insignificant correlation as its value does not lie between 0.1 to 0.6 .

\section{Conclusion and Recommendation}

The researcher discussed the impact of TV advertisement on children attitude in Karachi of the age of 10-15. Data which gathered it shows that children are very much aware about the products and they compare different products TV advertisement. Advertisement is the main purpose which not only changes the behavior regarding TV commercials it also change their buying behavior. The researcher used Rosster's Likert-scale to evaluate the attitude of children's toward advertisement. Children are very much aware about the good and bad aspects of TV advertisements. In this research study researcher found out six variables (poor taste, annoy, reality, good only, different and attract me). In this research the result show that depict is the most important factor that highly influence on children attitude towards TV advertisement. Marketer or advertising agencies should understand the psychic of children before launching any TV advertisement. So for the advertisers it's necessary to not ignore children because they are the important content of their advertising campaigns. It is also clear that if advertisements are created professionally they can be a good effective media for conveying the message in a child segment. Lastly advertisers are required to focus on the content of the advertisement, they can not only rely on comic and colors in the children related advertisement, over promising in the advertisement campaign must be avoided by them.

For the further study the researcher suggest that researcher's generalize the population at large content in further testing the Rosster's scale to find out whether the same test apply to different age group segments. The findings would useful for managers, marketing researchers and socialistic etc.

Further research should also extend in different nationalities. The research would be more interesting if it could examine between children and youth across several cultures.

\section{References}

[1]. Adler, R. P, Lesser, G. S, Merngff, L, Robertson, T, Rossiter, J, \& Ward, S, 1997, Research on the effects of television advertising to children. A review of the literature and recommendation for future research, US. Government Printing office, Washington. DC,

[2]. Atkinm C. Heald G. "The content of children toy and food commercials", Journal of communication, 39(2), 46-54

[3]. Barron S. J. Mok, J.J. Land, M, \& Kang T.Y. (1989). You are what you buy: mass mediated judgment of peoples worth, Journal of communalization, 39(2), 46-54

[4]. Barcus, F.E. 1980, The nature of television advertising to children. in; E. Palmer \&A Dorr, Children and faces of television (273285). New York Academic Press.

[5]. Bartsch, K., \& London K(2000), Children use of mental state information in selecting persuasive arguments, Development of Pyschology,35 352-365.

[6]. Borzekowski, D. L. G., \& Robinsion T. N. (2001) Pitching to preschoolers: The impact of television food commercial on sample of Head Start Children. Journal of the American Die tic Association, 101, 42-46.

[7]. Cantor, J. (1998). "Mommy I am scared". How TV and movies frighten children and what we can do to protect them, San Diego, CA:Hardcourt.

[8]. Caron, A. \& Ward S. (1975). Gift decisions by kids and parents, Journal of Advertising, 15(4), 12-20.

[9]. Carroll, J. (1984)/ The role of cognitive development in children understandings of their won feelings. Child development, 55, 1486-1492

[10]. Don A. (1986). Television and Children. A special medium for a special audience. Beverly Hilss. CA:Saga.

[11]. Donahue, T. (1975) Effect of commercials on black children. Journal of advertising Research. 15(6), 41-46.

[12]. Flavell, J. (1977), Cognitive development. Englewood Cliffs. NJ: Prentice Hall

[13]. Friestad, Mm \&Wright, P.(1994). The persuasion knowledge model: How cope with persuasion attempts. Journal of Consumers Research, 21(June), 1-31.

[14]. Galst. J. \& White. M., (1976).The unhealthy persuader. The reinforcing value of television and children's purchase influence attempts at the supermarket. Child development, 47, 1089-1096.

[15]. Gorn. G., \& Goldberg. M. (1982). Behavioral evidence of the effects of televised food messages on children. Journal of Consumer Research, 9,200-205. 
[16]. John D. R. (1999). Consumer Socialization of children. A retrospective look at twenty-five years of research: Journal of consumer Research. 26(December). 183-213.

[17]. Kline S. L \& Clinton, B.L. (1998). Development in children persuasive message practices,. Communication education, 47(April). $120-135$.

[18]. Kunkel.D. \& Gantz. W. (1992). Children Television Advertising in the multi-channel environment, Journal of Communication, 42(3), 134-152.

[19]. Macklin, M. C (1987). Preschoolers understanding of the information function of television advertising. Journal of consumer Research, 14(September), 229-339.

[20]. Palmer, E. Cantor, J., Drowrick, P. kUnkel D.Linn S U Wocox, B. (2004), Psychology implication of commercialization in the schools, Washing DC, American Psychological Association.

[21]. Rice, M. L. \& Woodsmail, L( 1988). Lessons from television:Childeren's words lerning when viewing child Development 59(2), 420-429.

[22]. Robertson. T \& Rossiter, J. (1977). Children Responsiveness to commercials. Journal of Consumer Research, 8, 144-153.

[23]. Selman, R. (1971) Taking another's perspective: Role-taking development in early childhood. Child development. 42. 1721-1734.

[24]. Silverman, W. Jaccard. J. \& Burke, A. (1988) Children's attitudes toward products and recall of product information over time. Journal of experimental Child Psychology, 45, 365-381

[25]. Singer, M. I., Slovak.K., Frieston, T. \& York..P(1998) Viewing preference, symptoms of psychological trauma, and violent behaviors among children who watch television. Journal of the American Academy of Child and Adolescent Psychiatry, 37(10)1041-048

[26]. Wells, D. M., \& Sachs, J. (1991). Persuasive strategies used by preschool children. Discourse Processes, 14, 55-77.

[27]. Wellman, H. M. (1990) The child's theory of mind. Cambridge. MA. MIT Press.

[28]. Young B. (1990) Television advertising and children. Oxford, Clarendon, Press.

[29]. Zuckerman, P. Ziegler, M, \& Stevenson. H. (1978). Children viewing of television and recognition memory of commercials. Child development, 49, 96-104.

[30]. Mc Neal, J.U. \& Ji M.F. (1999) Chinese children as consumers: an analysis of their new product information sources. Journal of Consumer Marketing, 16,4, 345-365.

[31]. Rossiter, J.R. (1977) Reliability of short test measuring children's attitudes toward TV commercials. Journal of Consumer Research.

[32]. Malhotra N.K. (1993) Marketing Research: An Applied Orientation. New Jersey: Prentice Hall.

[33]. Kotler, P. (2000) Marketing Management: The Millennium Edition. New Jersey: Prentice Hall. 